\title{
A Sociologia Econômica
}

STEINER, Philippe. São Paulo: Atlas, 2006.

LUCAS RODRIGUES AZAMBUJA*

O livro de Steiner é uma excelente introdução à sociologia contemporânea dos mercados, pois expõe as principais teorias e pesquisas deste campo do conhecimento sociológico, tendo em vista a sua relação com a teoria econômica. Entretanto, como uma introdução à sociologia econômica enquanto tal (como deixa entender o título), o livro deixa a desejar, na medida em que analisa apenas os estudos sobre os mercados e, deste modo, não cobre todos os temas da sociologia econômica. Mas como introdução à sociologia econômica dos mercados, a obra tem como mérito principal a exposição clara, didática e exaustiva deste assunto. Esta característica introdutória e didática fica clara ao longo das páginas nas quais encontramos destacadas e separadas do texto do livro enquanto tal, breves definições e explicações a respeito de questões, conceitos e correntes teóricas da economia e da sociologia, fazendo com que, assim, o livro seja acessível aos leitores sem conhecimento de uma ou de outra dessas duas ciências. Enfim, é um livro interessante tanto para os leitores iniciados quanto para os não iniciados nos estudos sociológicos sobre os mercados.

Contudo, A Sociologia Econômica não é apenas um trabalho de apresentação de um campo ou tema do conhecimento sociológico, mas, também, uma interessante interpretação a respeito da sociologia econômica. Nesta direção, o principal objetivo de Steiner é mostrar, através da exposição

\footnotetext{
* Bacharel em Ciências Sociais pela Universidade Federal do Rio Grande do Sul (UFRGS), colaborador do Grupo de Estudos "Trabalho na Sociedade Contemporânea" (www.ufrgs.br/ppgsocio), estudante de mestrado do Programa de Pós-Graduação de Sociologia da UFRGS e bolsista CNPq. lucas.ra@terra.com.br. Brasil.
} 
e sistematização dos principais estudos e teorias da sociologia econômica dos mercados, a relação de complementaridade entre esta última e a economia.

A introdução e o primeiro capítulo tratam justamente dessa relação entre economia e sociologia econômica, procurando destacar que a última nasce da "[...] insatisfação experimentada face à teoria econômica quando ela se aparta das demais ciências sociais" (STEINER, 2006: 2). No capítulo 1, o autor começa mostrando como as principais correntes da sociologia econômica clássica (weberiana, durkheiminiana e paretoniana) se posicionam com relação à economia. Com exceção de Durkheim e os membros da sua escola que criticavam duramente a teoria econômica, as duas outras correntes advogavam que a sociologia econômica deveria complementar e complexificar a abordagem da ciência econômica. Em seguida, Steiner escreve sobre as principais contribuições dessas correntes clássicas para a sociologia econômica contemporânea. No caso de Weber, Pareto e Schumpeter a contribuição reside especialmente na idéia de conceber as diversas modalidades que assume a ação econômica e, deste modo, ir além da figura do homo oeconomicus da teoria econômica ortodoxa. A escola durkheiminiana apontou para o papel das instituições e representações sociais nas relações econômicas. Por fim, o capítulo primeiro aborda brevemente a definição de Nova Sociologia Econômica de Mark Granovetter. Steiner critica este último, em razão de que a Nova Sociologia Econômica não seria tão nova assim, pois sua démarche, na visão de Steiner, guarda semelhanças substantivas com a sociologia econômica clássica. Neste sentido, o autor prefere falar em sociologia econômica clássica e contemporânea do que em Nova e Velha (como o faz Granovetter). Cabe aqui uma pequena crítica a Steiner: nessa retomada da história da sociologia econômica, o autor não menciona a corrente economy and society formulada por Parsons e Smelser que, por seu turno, também propunha uma articulação entre teoria econômica e teoria sociológica. 
Nos capítulos seguintes, Steiner aborda a sociologia econômica dos mercados propriamente dita. O autor começa o capítulo 2 definindo brevemente a abordagem formalista e abstrata da teoria econômica sobre os mercados e, neste sentido, defende que "[a] o estudar as conseqüências lógicas do comportamento egoísta e as interdependências existentes no interior de um sistema de mercados, a teoria econômica produz conhecimentos úteis à ciência social" (STEINER, 2006: 35). Contudo, apesar desses "conhecimentos úteis" (que Steiner não chega a explicitar quais sejam), a economia não é suficiente para entender os mercados, pois ela está apoiada em premissas teóricas equivocadas, quais sejam: 1) os indivíduos agem a partir de uma situação de informação perfeita a respeito somente dos sinais emitidos pelo repertório de preços do mercado; 2) os atores agem sem nenhum grau de incerteza quanto às qualidades e propriedades dos bens de um mercado, ou quanto ao cenário futuro. Na avaliação de Steiner, essas premissas levaram a economia a desconsiderar o papel dos fatores sociais nos fenômenos de mercado. Neste sentido, é por meio da inserção do social que a sociologia econômica, para o autor, pode realizar uma contribuição significativa para a economia, na direção de uma melhor compreensão do mercado. Assim, Steiner chama a atenção para quatro modalidades através das quais a sociologia econômica vem inserindo o social nas suas análises sobre o mercado: 1) inserção estrutural - consiste na identificação da função das relações sociais na origem histórica e no funcionamento dos mercados; 2) cultural - o papel dos valores culturais no avanço ou contenção das relações mercantis (origem) e a significação cultural que estas últimas assumem; 3) política - o modo como instituições e interesses políticos e regulações jurídicas influenciam na origem, funcionamento e significado cultural dos mercados; 4) cognitiva - quais são os sistemas de classificação, racionalidades e formas de conhecimento e representação social que estão na origem e funcionamento dos mercados. Nos capí- 
tulos seguintes, então, Steiner irá expor estudos de sociologia econômica que apreendem o papel mediador ou interveniente dos fatores associados a essas modalidades de inserção do social na origem (capítulo 3), funcionamento (capítulo 4) e significação cultural (capítulo 5) dos mercados.

Com relação à origem, o autor procura mostrar como os estudos sociológicos desvendam a construção social dos mercados, ou seja, de que modo mediações sociais entram em jogo, num determinado período de tempo, para o surgimento de um mercado ou, ainda, que fatores de natureza social "sustentam" uma dada configuração que um mercado assume. São pesquisas que dão conta dessas questões estudando casos de mercados de bens (compra/venda de morangos na França); mercados relativos a um setor industrial (produção/distribuição de energia elétrica nos EUA); mercado de trabalho e financeiro. Além disso, Steiner analisa estudos que abordam a construção social de duas dimensões relativas aos mercados, a saber, o uso do dinheiro e o comportamento competitivo. Deste modo, é possível, neste capítulo, ter-se uma visão panorâmica do papel de fatores sociais na origem de diversas modalidades de mercado e aspectos relativos a ele. Fatores sociais como as redes de relações sociais; instituições e representações sociais que estabelecem formas de regulações sobre o comportamento dos agentes; valores culturais e modalidades de racionalidade que interferem na ação dos atores no interior de um mercado. Tudo isso, sem que se perca de vista o papel dos fatores propriamente econômicos, o que, por sua vez, reforça a tese de Steiner sobre a complementaridade entre sociologia econômica e economia.

Em seguida, o autor explora muito bem a tendência dos estudos de sociologia econômica contemporânea em explicar o funcionamento dos mercados através do recurso teórico-metodológico da análise de redes. Neste sentido, este recurso é utilizado pelos sociólogos para demonstrar a pertinência das relações sociais no funcionamento dos mercados e, assim, romper com 
o modelo teórico tradicional da economia, baseado na figura do homo oeconomicus. Para Steiner, a importância da análise de rede está, portanto, na sua capacidade de fornecer uma outra maneira de conceber o ator e a ação econômica dentro de sua articulação com a estrutura de relações sociais e, então, explicar o funcionamento dos mercados com base nessa concepção. Nesta direção, os estudos que Steiner aborda neste capítulo quarto ilustram o modo como a estrutura da rede e a posição e a qualidade dos vínculos que os atores detêm nela influenciam, de um lado, possibilitando ou restringindo a própria ação econômica e os resultados que esta última atinge ou não e, por outro, conformando uma determinada característica de funcionamento de um dado mercado, por exemplo, o grau de volatilidade dos preços. Finalmente, com relação à articulação entre teoria econômica e sociologia econômica, o autor destaca que a análise de rede permite a construção de modelos formais matemáticos corroborando, deste modo, o diálogo entre sociólogos e economistas.

Todavia, com relação à significação cultural e inserção cognitiva das relações e ocorrências mercantis, o diálogo entre economia e sociologia econômica é difícil, na medida em que esta última, de um lado, procura mostrar que outras formas de conhecimento e representações sociais que não aquelas relativas ao repertório de informações emitido pelos mercados, os agentes mobilizam para conduzir as suas ações e, de outro, como a própria economia enquanto conhecimento produz "efeitos de teoria", no comportamento econômico concreto. Deste modo, Steiner sustenta no capítulo quinto que a sociologia econômica assume uma posição crítica denunciando a teoria econômica na sua tentativa de se apresentar como discurso descolado do contexto social e dotado de objetividade técnica.

Finalizando, o livro de Steiner é uma interessante apreciação da sociologia econômica dos mercados, que tenta articulá-la com a teoria econômica. Talvez em função dessa tentativa de articulação, o autor não explore 
suficientemente as fissuras, debates e tensões seja internos à própria sociologia econômica, seja na sua relação com a economia. Simultaneamente, trata-se de um livro que introduz de maneira clara e didática essa área do conhecimento sociológico sem incorrer em simplificações.

\section{Resumo}

O livro de Philippe Steiner (A Sociologia Econômica) consiste numa introdução e apreciação dos estudos da sociologia econômica sobre os mercados. O autor aborda trabalhos que tratam desde a questão da construção social dos mercados, passando pela explicação do funcionamento destes últimos, até a sua significação cultural na sociedade moderna. Através da análise desses estudos, o autor defende a tese de uma relação de complementaridade entre teoria econômica e sociologia econômica. Trata-se, assim, de um livro que possui um caráter didático, pois explica e sistematiza um campo do conhecimento para o leitor não iniciado, e, simultaneamente, apresenta elementos de reflexão original a respeito deste mesmo campo.

Palavras-chave: mercados, teoria econômica, sociologia econômica.

Recebido: $14 / 08 / 06$

Aceite final: 22/11/06 


\section{A Sociologia Econômica (Economic sociology) STEINER, Philippe. São Paulo: Atlas, 2006.}

\section{Lucas Rodrigues Azambuja}

Philippe Steiner's A Sociologia Econômica is an introduction and an appreciation of economic sociology studies on markets. The author approaches works including from the issue of social construction of markets to explaining their workings to its cultural meaning in modern society. Through the analysis of those studies, the author advocates a complementary relationship between economic theory and economic sociology. Therefore, it has a textbook character, since it explains and systematizes a field of knowledge for beginners and, at the same time, it presents elements of original reflection on the field.

Key words: markets, economic theory, economic sociology. 